\title{
Erratum to: Predicting technique and patient survival over 12 months in peritoneal dialysis: the role of anxiety and depression
}

\author{
Konstadina Griva $^{1,2}$ • Augustine W. C. Kang ${ }^{1}$ Zhen Li Yu' ${ }^{1}$ Vanessa Y. W. Lee ${ }^{1}$. \\ Sotirios G. Zarogiannis ${ }^{3} \cdot$ Choong Meng Chan ${ }^{4} \cdot$ Marjorie Foo $^{4}$
}

Published online: 11 March 2016

(C) Springer Science+Business Media Dordrecht 2016

\section{Erratum to: Int Urol Nephrol \\ DOI 10.1007/s11255-015-1191-x}

The names of two authors were misspelt in the original publication. The correct names are as follows: Sotirios G. Zarogiannis and Choong Meng Chan.

The affiliation of the co-author, Sotirios G. Zarogiannis, was incorrect in the published version. The correct affiliation should read as Department of Physiology, Faculty of Medicine, University of Thessaly, Larissa, Greece.

The online version of the original article can be found under doi:10.1007/s11255-015-1191-x.

Konstadina Griva

psygk@nus.edu.sg

1 Department of Psychology, National University of Singapore, Block AS4, \#02-28, 9 Arts Link, Singapore 117570, Singapore

2 Health Services Research Group, City University London, London, UK

3 Department of Physiology, Faculty of Medicine, University of Thessaly, Larissa, Greece

4 Department of Renal Medicine, Singapore General Hospital, Singapore, Singapore 